\title{
Construction Risk Taxonomy: An International Convergence of Academic and Industry Perspectives
}

\author{
${ }^{1}$ Kristen Barlish, ${ }^{2}$ Alberto De Marco and ${ }^{3}$ Muhammad Jamaluddin Thaheem \\ ${ }^{1}$ School of Sustainable Engineering and the Built Environment, \\ Arizona State University, Tempe, Arizona, USA \\ ${ }^{2}$ Department of Management and Production Engineering, Politecnico di Torino, Italy \\ ${ }^{3}$ Department of Urban Studies and Planning, Politecnico di Torino, Italy
}

Received 2013-04-16, Revised 2013-06-24; Accepted 2013-06-24

\begin{abstract}
Risk management is a topic heavily researched and important for industry professionals. Both academic and industry perspectives are critical to advancing this field, especially in risk identification and taxonomy. A unique comparison and convergence of these perspectives is developed in order to understand the most relevant risks for projects and to ensure they are addressed in the risk management process. This comparison is created via a content analysis of the relevant literature and a survey to industry professionals. The differences and similarities among risks are analyzed, revealing that both perspectives emphasize financial/economic risks. The literature tends to focus on political; acts of God classified risks, whereas the industry places emphasis on regulatory risks. An elaboration of variations is performed aiming to improve the literature-based taxonomy taking into account the industry perspective to ensure its risk management process responds to these risks and provides a clearer focus towards future research.
\end{abstract}

Keywords: Engineering and Construction, Risk Identification, Risk Management, Survey

\section{INTRODUCTION}

Construction projects are risky and risk identification is challenging (Hillson, 2002a), as evidenced by projects that exceed budget, go beyond the schedule and have compromised specifications (Baloi and Price, 2003; Meyer et al., 2002). A KPMG (2012) survey of 161 construction and engineering executives revealed that only 36 percent feel their project review processes are very efficient. The literature (Meyer et al., 2002; Royer, 2000) and related surveys (Akintoye and MacLeod, 1997; KPMG, 2012; Lyons and Skitmore, 2004) have revealed that past experience of individuals is the backbone or the top technique for risk management in projects. Therefore, research pertaining to this commonly understood risk management technique that could increase its effectiveness would be greatly beneficial. Furthermore, collecting, analyzing and synergizing multiple perspectives of both literature and industry experiences would contribute to an overall impactful risk management process in construction projects.

\subsection{Background}

Taken separately, risk is "an uncertain event or condition that, if occurs, has a positive or negative effect on a project objective" and, together, risk management is "the process of identifying, analyzing and responding to project risk" (PMBoK, 2008). The critical points of these definitions are that both positive and negative sides are considered in addition to the various steps of the risk management process throughout the lifecycle of a project. A large number of tools and techniques exist for risk identification, such as brainstorming, interviews, use of specialists, SWOT analysis, checklists, feedback, workshops, prompt list, questionnaires, delphi group, normal group techniques and various diagrammatic

Corresponding Author: Kristen Barlish, School of Sustainable Engineering and the Built Environment, Arizona State University, Tempe, Arizona, USA 
techniques (cause effect diagram, influence diagrams) (Hillson, 2002a). Regardless of the tool selected, the important point is that risk identification is an iterative process and to be useful, the risks must be properly documented in order to be a source of learning for future projects. Therefore, the development of a taxonomy of risks will enable proper identification of those commonly encountered risks, based on the literature and the industry feedback.

\subsection{Objective}

The common medium for the collection of industry perspectives is the survey. Prior to creation of this industry taxonomy survey, other surveys were analyzed on the topic of construction risk management. A preliminary review uncovered surveys with a primary focus on risk management practices and found that experience is the chief technique for individuals to identify and manage risks (Burchett et al., 1999; KPMG, 2012). Other surveys identified sector or country-specific risks rated based on criticality (Thomas et al., 2003). Additional surveys required respondents to rate risks based on importance and made an average rating visible (Choudhry and Iqbal, 2012). Tang et al. (2007) highlight and pinpoint some of the challenges in fifteen historical risk management surveys, such as lacking a multi-disciplinary perspective of risks, using an improper scale (such as a Likert scale of importance) and creating improper comparisons of priorities versus frequency risks. Confusion in perspectives and between an important risk and a frequently encountered risk (mutually exclusive qualities) can be encountered. Therefore, there are gaps in past surveys regarding the reporting of the risks most recently encountered on projects and the move to a more international perspective.

As a result of these identified survey gaps, it is also hypothesized that there is a difference between academic and industry perspectives regarding the prioritization of risks, making it difficult to determine the most important risks to address in new projects and future research. The purpose of this study is to answer the question-What are the different types of construction risks according to the literature and construction industry professionals' experiences? The objectives are to:

- Analyze the gap via a targeted literature review and content analysis

- Develop a framework taxonomy

- Create a literature-inspired risk matrix

- Distribute a survey to the industry to obtain an industry-inspired risk matrix from the results of the survey

- Build a comparison of literature-inspired and industry-inspired matrices and identify the risks recognized by both perspectives
- Elaborate and reflect upon the differences and similarities between the two perspectives

- Establish the implications and possible uses of this analysis

\subsection{Research Methodology}

In order to properly extract data from the literature, a type of textual or content analysis was carried out. Content analysis has been described as the collection, organization and structuring of information in a standardized format that enables the analysis and drawing of inferences from information to find meaning (GAO, 1996; Stemler, 2001). Historically, content analysis has been applied to investigate the existence or absence of concepts contained in a series of data in the social sciences and health studies (Pisano et al., 2011) and to identify trends that later become the basis of a survey. Thus, when the data under consideration is textual and the evaluations lead to useful comparisons; content analysis is a good approach (Stemler, 2001). The content analysis carried out here is more distinct, as information is written and from peer-reviewed journals versus interview data, case studies and related reports. The steps to the analysis were adopted as (GAO, 1996; Stemler, 2001): (1) define objective; (2) define material to be analyzed; (3) set units of analysis; (4) establish rules of coding; (5) check for reliability; (6) analyze and interpret the information; and (7) validate results. The purpose of this content analysis was to develop a matrix developed from the literature and framework taxonomy to become the basis of a survey to the industry and to compare to results of the survey. From the comparison of literature-inspired and industry-inspired matrices an explanation of the phenomenon of variance is provided.

\subsection{Creation of the Taxonomy and Literature- Inspired Matrix}

The taxonomy was created via a general and targeted literature review that was performed regarding construction risk classification and taxonomies. The reviews uncovered 18 sources of literature (mostly peerreviewed journal articles), as shown in Table 1, regarding the subjects of construction risk analysis, construction risks commonly encountered and general frameworks. Following the six steps to the content analysis (GAO, 1996; Stemler, 2001) the objective was uncovering what are the different types of construction risks encountered in construction projects according to the literature (development of a literature-inspired priority matrix) and the material to be analyzed was defined as literature that suggested the types of risks present in construction projects. 
Table 1. Construction risk identification taxonomy sources

\begin{tabular}{ll}
\hline Author & Focus/Summary \\
\hline Sun and Meng (2009) & Taxonomy for causes and effects \\
Hillson (2002b) & Proposed Risk Breakdown Structure (RBS) \\
Mustafa and Al-Bahar (1991) & Used the analytical hierarchy process \\
Leung et al. $(1998)$ & A knowledge-based system \\
El-Sayegh (2008) & Risk assessment and allocation in the UAE \\
Akintoye and MacLeod (1997) & Risk analysis and management \\
Tchankova (2002) & Risk identification \\
Zhi (1995) & Risk management overseas \\
Chapman (2001) & Controlling influences in design management \\
Hastak and Shaked (2000) & International construction risk assessment \\
Dey (2001) & Decision support system \\
Dey (2010) & Used the analytical hierarchy process and map \\
Shen (1997) & Risk management in Hong Kong \\
Dikmen et al. $(2008)$ & Developed tool for post-project assessment \\
Tserng et al. $(2009)$ & Ontology-based, through project life cycle \\
Zou et al. $(2007)$ & Key risks in construction projects in China \\
Tah et al. (1993) & Used linguistic approximation \\
Baloi and Price (2003) & Modeling global risk factors affecting cost \\
\hline
\end{tabular}

A construction risk taxonomy matrix was created that divided risks according to three levels. While other risk matrices have divided the levels according to a variation of factors such as the location of risk, source and/or particular organization, the overall analysis ultimately discussed the sources of the risks (Dey, 2001; Shen, 1997; Tah et al., 1993; Zou et al., 2007).

Therefore, the risks in this risk taxonomy matrix are divided accordingly into a combination of these classifications in Fig. 1. Level one classifies the risk as either internal or external to the construction vendor, level two categorizes the risk according to its source or organization responsible and level three captures the detail. Internal risks are those that are project related and usually fall under the control of the construction vendor and are then categorized according to the party who might be the originator of risk events such as owner, designer, contractor.

External risks are those risks that are beyond the control of the construction vendor and are categorized according to a more macro perspective (Zhi, 1995). To properly organize and utilize large amounts of data, the Risk-Breakdown Structure/Hierarchical Risk-Breakdown Structure (RBS/HRBS) is commonly suggested (Hillson, 2002b); however, at this preliminary stage, a type of taxonomy (Sun and Meng, 2009) is utilized that focuses more on proper identification than a particularity priority. The literature-inspired matrix followed the rules of coding according to the emergent principle (Stemler, 2001). To check for reliability, an external reviewer extracted a random sample of data and checked it against the sources.

\subsection{Industry Survey}

An industry survey to construction professionals was created to uncover the most commonly encountered risks based on their past projects. The survey was made available online from March until May 2012 via social networks and professional emails. A total of 199 responses were received, which exceeded the required return sample size according to Cochran (1963). A 7 percent margin of error was considered as acceptable given the norm of 5 percent for categorical data and 3 percent for continuous data (Krejcie and Morgan, 1970):

$$
\text { no }=\frac{t^{2} * p \cdot q}{d^{2}}
$$

Where:

no $=$ Required return sample size

$\mathrm{t} \quad=$ Value of selected alpha level

p.q $=$ Estimate of variance

$\mathrm{d}=$ Acceptable margin of error

$$
\begin{gathered}
\text { no }=\frac{1.96^{2} * 0.25}{0.07^{2}}=196 \\
\mathrm{t}=1.96(\alpha=0.05)
\end{gathered}
$$

p.q $=$ maximum possible proportion $*(1-$ maximum possible proportion):

$$
\begin{gathered}
0.5 * 0.5=0.25 \\
d=0.07
\end{gathered}
$$


Kristen Barlish et al. / American Journal of Applied Sciences 10 (7): 706-713, 2013

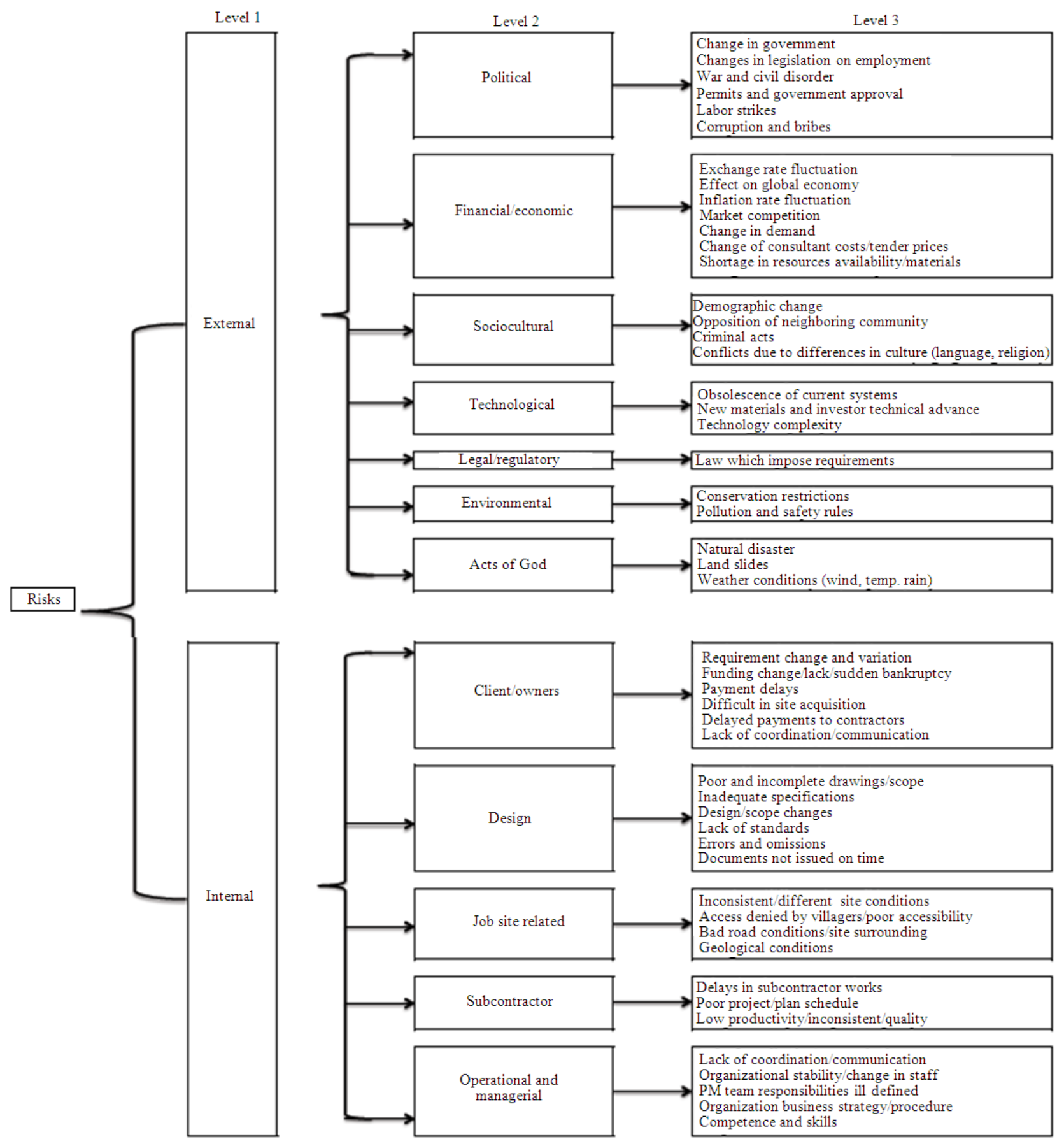

Fig. 1. Proposed taxonomy

Overall, the results revealed that the respondents came from a variety of backgrounds (design/engineering and general contracting), are divided internationally and have high levels of experience (at least 15 years) in the construction sector. In detail, the types of companies were: Design/engineering (33\%); general contractor 
(31\%); consultant (17\%); subcontractor (4\%); services (4\%); and other $(13 \%)$. Geographically, respondents came from the North and South America (62\%); Europe (23\%); Asia (9\%); Africa (5\%); and Australia (2\%). The positions of the respondents were: engineer/designer (29\%); project manager (27\%); director (19\%); Site manager $(6 \%)$; project risk manager $(2 \%)$; and other $(18 \%)$. The years of experience were: greater than 15 years $(45 \%) ; 15-11$ years $(13 \%) ; 10-5$ years $(20 \%)$; and less than 5 years $(22 \%)$. Given the geographic position and the variety of respondents, bias of selecting samples can be reasonably avoided and the data collected can, to a large extent, be seen as representative of the general construction industry.

\subsection{Industry-Inspired Matrix}

After background information was collected, the survey asked the participants to identify the ten most common external and internal risks that they have encountered on their past projects. The industry-inspired matrix was created based on these results. Another survey carried out (Tang et al., 2007) validated these results, as it found the five most important risks to be somewhat similar as: poor quality of work, premature failure of the facility, safety, inadequate or incorrect design and financial risk. Therefore, it can be hypothesized that the rate of innovation and change in understanding and perception of risk is relatively faster in the industry than the literature. Preference change over time and under varied conditions; mostly aided by experience and exposure, which are readily available to the members of industry. Almost half of most frequently reported risks from industry point of view have only appeared over the last 5 years, suggesting a change of preferences and perceptions. Therefore, the survey results are validated on the industry side; however, they are missing a final comparison with the literature.

\subsection{Comparison of Literature and Industry Matrices}

After the literature-inspired and industry-inspired matrices were developed, the risks both perspectives identified were extracted. In comparing the matrices' top ten risks, it was found that not all risks in the literature matrix were in the industry matrix. In Table 2 , the external and internal risks in common to both perspectives can be seen.

\subsection{Elaboration of Results and Implications}

Patterns and relationships were investigated regarding the similarities and differences between the two perspectives, which uncovered some interesting findings. Comparing the risk categories with each risk uncovers that both perspectives see that external risks of the financial/economic type are most commonly encountered. Both literature and industry top ten matrices contained the external risks: permits and government approval, weather conditions (wind, temp, rain), shortage in resources availability/materials and inflation rate fluctuation. The internal risks commonly encountered were from the clients/owners and designers categories. Both literature and industry top ten matrices contained the internal risks: lack of coordination/communication, design/scope changes, poor and incomplete drawings, requirements change and variation and delays in subcontractor works (Table 3). The risks that were not common to both literature and industry and were not contained in the top ten should also be discussed to provide a complete representation and to gain insight into perceptions. The literature tends to have a greater emphasis on those risks pertaining to the external categories of: political and acts of God; whereas the industry emphasizes: regulatory and financial/economic.

For example, the financial/economic risks of: effect on global economy, market competition, change in demand and change of consultant costs/tenders prices were commonly encountered according to the industry, but did not make it to the literature top ten.

It can be argued here that the industry is more concerned with external risks relating to the economic environment, while the literature is more concerned with political risks such as change in government and legislations on employment. Also, it is evident that the industry sees risks relating to the economy as imminent and has a greater tendency to affect their projects than the government. Regarding internal risks that did not make it to the top ten, the industry saw design risk as commonly encountered, while the literature was concerned with job site related risks. It can be perceived that the industry is more concerned with the impact of third parties on their projects than that relating to the technical work, such as site conditions.

Further, the literature views the risk scenarios with a much wider lens whereas industry is more concerned by the immediate threats. Also the rate of renewal and up gradation of literature is less than that of compared to industry for obvious reasons. One such example is the explanation of 'inflation risk', ranked 1 st by literature and 10th by industry: in the times of financial crisis, the inflation is controlled and the risk is reduced, decreasing its frequency and severity. Also, with experience, the industry has learnt to use sophisticated financial and contractual tools to control and manage this risk. 
Table 2. Risks Comparison

\begin{tabular}{llll}
\hline Internal risks & & External risks & \\
\hline Literature & Industry & Literature & Industry \\
\hline Poor and incomplete & Lack of coordination/ & Inflation rate & Permits and government \\
Drawings & communication & fluctuation & approval \\
Low productivity/ & Design/scope & Weather \\
Incompetence/quality & changes & Shertuation & conditions \\
Inconsistent/different & Payment & availability/materials & Market \\
site conditions & delays & Changes in & Competition \\
Requirements & Poor and & legislations on employment & Shortage in resources \\
change and variation & incomplete drawings & Natural & availability/materials \\
Funding change/ & Inadequate & Disaster & Change \\
lack/Sudden Bankruptcy & specifications & Weather & in demand \\
Lack of coordination/ & Requirements & conditions & Law which \\
communication & change and variation & Permits and & impose requirements \\
Design/ & Delays in & government approval & Pollution \\
scope changes & subcontractor works & Land & and safety rules \\
Delays in & Documents not & slides & Change of consultant \\
subcontractor works & issued on time & Change in government & costs/tenders prices \\
Geological Conditions & Errors and omissions & Obsolescence & Effect on Global Economy \\
PM team & Poor project/ & of current systems & Inflation \\
responsibilities ill defined & plan schedule & rate fluctuation
\end{tabular}

Table 3. Highlighted Risks (in no particular order of importance)

\begin{tabular}{ll}
\hline Internal risks & External risks \\
\hline Poor and incomplete drawings & Inflation rate fluctuation \\
Lack of coordination or communication & Permits and government approval \\
Design/scope changes & Shortage in resources availability/materials \\
Requirements change and variation & Weather conditions \\
Delays in subcontractor works & \\
\hline
\end{tabular}

Further, literature seems to underestimate the otherwise 'soft' appearing scenarios, such as 'human factor' and 'ground realities', when it comes to prioritizing the risk. For instance 'Lack of coordination/communication', ranked 6th by literature and $1 \mathrm{st}$ by industry, establishes that the literature assumes such skills to be already provided with, being a bit too idealistic. Accordingly, strict coordination between the stakeholders may ensure timely and effective management of a number of risks; otherwise harmless looking factors can hugely contribute to major issues ranging from delays and cost overruns to severe accidents and physical damages. Furthermore, 'weather conditions', ranked 6th by literature and 2nd by industry, also demonstrates the hypothecation of literature: the ground realities are often more challenging than anticipated and a small change in weather condition may mean a huge impact on project execution, thus creating a potential loss.

\section{CONCLUSION}

This study addressed the gaps between academic and industry perspectives regarding the prioritization of risks, thus providing clarity to determine the most important risks to address in new projects and future research. Answers were provided to the central question-What are the different types of construction risks according to the literature and construction industry professionals' experiences? Through literature and content analysis, framework taxonomy was developed and literature inspired risk matrix was created. Through the distribution of an international survey and the analysis of its results, an industryinspired matrix was constructed and compared to the literature-inspired matrix. The similarities and differences were discussed. From this, industry and academia can benefit in working towards the development of risk management practices and tools. 
The comparison performed and the resulting elaboration is significant as it combines dual perspectives and captures the critical components to be considered on future projects. Both industry and academic sides are portrayed. The comparison revealed that the original hypothesis that there is a gap between industry and academic perspectives regarding risks in construction projects is correct. The need to build a more complete, recent and industry-focused perspective of risk taxonomy was highlighted. A targeted literature review and content analysis lead to the development of framework taxonomy. The literature inspired matrix was populated by the responses from the survey. Finally, the comparison of these matrices revealed the commonalities and differences between perspectives of risk. Through the survey, analysis and matrices developed, the most important risks to address in new projects and future research were identified via a comparison of the two matrices and their detailed analysis.

Construction professionals can utilize these matrices to deliver practical risk management. They serve as a thinking tool or discussion prompt to ensure the team has looked at the project and its environment from different perspectives.

The matrices do not encompass the entire risk management process, thus it is recommended that they are combined with other techniques. Future research should further explore financial/economic and client/owner risks, establishing methods to mitigate these frequently encountered risks. Future industry surveys should seek to obtain a larger sample size, use multiple languages and mediums to reach out to a larger population of construction industry professionals.

\section{REFERENCES}

Akintoye, S.A. and M.J. MacLeod, 1997. Risk analysis and management in construction. Int. J. Project Manage., 15: 31-38. DOI: 10.1016/S02637863(96)00035-X

Baloi, D. and A.D.F. Price, 2003. Modeling global risk factors affecting construction cost performance. Int. J. Project Manage., 21: 261-269. DOI: 10.1016/S0263-7863(02)00017-0

Burchett, J.F., V.M.R. Tummala and H.M. Leung, 1999. A world-wide survey of current practices in the management of risk within electrical supply projects. Construct. Manage. Econ., 17: 77-90. DOI: 10.1080/014461999371844
Chapman, R.J., 2001. The controlling influences on effective risk identification and assessment for construction design management. Int. J. Project Manage., 19: 147-160. DOI: 10.1016/S02637863(99)00070-8

Choudhry, R.M. and K. Iqbal, 2012. Identification of risk management system in construction industry in Pakistan. J. Manage. Eng., 29: 42-49. DOI: 10.1061/(ASCE)ME.1943-5479.0000122

Cochran, W.G., 1963. Sampling Techniques. 2nd Edn., John Wiley and Sons, New York, pp: 413.

Dey, P.K., 2001. Decision support system for risk management: A case study. Manage. Decision, 39: 634-649. DOI: 10.1108/00251740110399558

Dey, P.K., 2010. Managing project risk using combined analytic hierarchy process and risk map. Applied Soft Comput., 10: 990-1000. DOI: 10.1016/j.asoc.2010.03.010

Dikmen, I., M.T. Birgonul, C. Anac, J.H.M. Tah and G. Aouad, 2008. Learning from risks: A tool for postproject risk assessment. Automation Construct., 18: 42-50. DOI: 10.1016/j.autcon.2008.04.008

El-Sayegh, A.M., 2008. Risk assessment and allocation in the UAE construction industry. Int. J. Project Manage., 26: 431-438. DOI: 10.1016/j.ijproman.2007.07.004

GAO, 1996. Content analysis: A methodology for structuring and analyzing written material. United States General Accounting Office: Program Evaluation and Methodology Division.

Hastak, M. and A. Shaked, 2000. ICRAM-1: Model for international construction risk assessment. J. Manage. Eng., 16: 59-69. DOI: 10.1061/(ASCE)0742-597X(2000)16:1(59)

Hillson, D., 2002a. Extending the risk process to manage opportunities. Int. J. Project Manage., 20: 235-240. DOI: $10.1016 / \mathrm{S} 0263-7863(01) 00074-6$

Hillson, D., 2002b. Use a Risk Breakdown Structure (RBS) to understand your risks. Proceedings of the Project Management Institute Annual Seminars and Symposium, Oct. 3-10, San Antonio, Texas USA.

KPMG, 2012. The great global infrastructure opportunity: Global construction survey 2012.

Krejcie, R.V. and D.W. Morgan, 1970. Determining sample size for research activities. Educ. Psychol. Measur., 30: 607-610.

Leung, H.M, K.B. Chuah and V.R. Tummala, 1998. A knowledge-based system for identifying potential project risks. Omega, Int. J. Manage. Sci., 26: 623638.DOI: 10.1016/S0305-0483(98)00010-3 
Lyons, T. and M. Skitmore, 2004. Project risk management in the Queensland engineering construction industry: A survey. Int. J. Project Manage., 22: 51-61. DOI: 10.1016/S02637863(03)00005-X

Meyer, A., C.H. Loch and M.T. Pich, 2002. From variation to chaos. MIT Sloan Manage. Rev., 43: 60-67.

Mustafa, M.A. and J.F. Al-Bahar, 1991. Project risk assessment using the analytic hierarchy process. IEEE Trans. Eng. Manage., 38: 46-52. DOI: 10.1109/17.65759

Pisano, P., G. Vagnani, M. Pironti, M. Simoni and M. Giraudo, 2011. Understanding the strategic organization propensity through "managerial discussion and analysis". Int. J. Trade Econ. Finance, 2:147-153.

PMBoK, 2008. The Project Management Body of Knowledge. 1st Edn., Project Management Institute, Inc., Newtown Square, PA, USA.

Royer, P.S., 2000. Risk management: The undiscovered dimension of project management. Project Manage. J., 31: 6-13.

Shen, L.Y., 1997. Project risk management in Hong Kong. Int. J. Project Manage., 15: 101-105. DOI: 10.1016/S0263-7863(96)00045-2

Stemler, S., 2001. An overview of content analysis. Practical Assess. Res. Eval., 7.

Sun, M. and X. Meng, 2009. Taxonomy for change causes and effects in construction projects. Int. J. Project Manage., 27: 560-572. DOI: 10.1016/j.ijproman.2008.10.005
Tah, J.H.M., A. Thorpe and R. McCaffer, 1993. Contractor project risks contingency allocation using linguistic approximation. Comput. Syst. Eng., 4: 281-293. DOI: 10.1016/0956-0521(93)90052-X

Tang, W., M. Qiang, C.F. Duffield, D. M. Young and Y., $\mathrm{Lu}, 2007$. Risk management in Chinese construction industry. J. Construct. Eng. Manage., 133: 944-956. DOI: 10.1061/(ASCE)0733-9364(2007)133:12(944)

Tchankova, L., 2002. Risk identification-basic stage in risk management. Environ. Manage. Health, 13: 290-297. DOI: 10.1108/09566160210431088

Thomas, A.V., S.N. Kalidindi and K. Ananthanarayanan, 2003. Risk perception analysis of BOT road project participants in India. Construct. Manage. Econ., 21: 393-407. DOI: 10.1080/0144619032000064127

Tserng, H.P., S.Y.L. Yin, R.J. Dzeng, B. Wou and M.D. Tsai et al., 2009. A study of ontology-based risk management framework of construction projects through project life cycle. Automation Construct., 18: 994-1008. DOI: 10.1016/j.autcon.2009.05.005

Zhi, H., 1995. Risk management for overseas construction projects. Int. J. Project Manage., 13: 231-237. DOI: 10.1016/0263-7863(95)00015-I

Zou, P.X.W., G. Zhang and J. Wang, 2007. Understanding the key risks in construction projects in China. Int. J. Project Manage., 25: 601-614. DOI: 10.1016/j.ijproman.2007.03.001 